\title{
La representación de los consumidores en las convenciones colectivas de consumo en Argentina
}

Lucio Andrés Terrasa ${ }^{87}$

Universidad Nacional del Nordeste de Argentina

lucio.andres@terrasa.com.ar

Fecha de recibido: Noviembre 2016/ Fecha de aprobación: Diciembre 2016

\section{Resumen}

El presente trabajo pretende plantear un problema a resolver: ¿cómo debe lograrse la representación de los consumidores en las convenciones colectivas de consumo?

Anticipamos al lector que no intentamos ni logramos en este estudio dar una solución acabada al interrogante planteado, sino que lo analizamos y ponemos a consideración de la comunidad científica posibles alternativas a la cuestión problemática.

Se utilizó un enfoque metodológico descriptivo, analizando doctrina y normativa de Argentina y Brasil; básico, ya que se buscó generar conocimiento, sin que sea de aplicación inmediata al medio o realidad actual; de corte transversal, o sea, acotado principalmente a la normativa vigente en Argentina y Brasil.

Llegamos a la conclusión de que los principales problemas que se plantean son la legitimación de la/s asociación/es que pretendan representar a los consumidores, así como la falta de cohesión del grupo representado.

Ante estos problemas proponemos como solución a desarrollar el establecimiento de un procedimiento administrativo que asegure la idoneidad de la asociación en cuestión, así como también que, en el acto de consumo, el consumidor sea informado de sus derechos y de quién lo representa.

\section{Palabras clave}

Consumidores / Representación / Convenciones colectivas de consumo

${ }^{87}$ Doctorando en Derecho por la Universidad Nacional del Nordeste de Argentina, Especializando en Derecho Administrativo por la Universidad Nacional del Nordeste, abogado Especialista en Derecho del Trabajo, UCA, 2010-2011, 
This work aims at presenting a problem to solve: How the consumer representation must be achieved in collective consumer agreements?

We anticipate the reader not to try and achieve in this study give a finished solution to the question posed, but analyze it and give a careful consideration to the possible alternatives in the scientific community to the problem involved.

The methodological description approach analysis of doctrine and rules of Argentina and Brazil were used in order to create knowledge, without it being immediately applicable to the environment or reality at present, cross-section, limited mainly to current regulations in Argentina and Brazil.

We conclude that the main problems that arise are the legitimization of associations seeking to represent consumers, and the lack of cohesion of the group represented. Given these problems, we propose as a solution to develop the establishment of an administrative procedure to ensure the adequacy of the association concerned, as well as that in the act of consumption, the consumer is informed of their rights and who represents.

Consumers / Representation / Collective Consumer Agreement

\section{Tabla de contenido}

I. Introducción. 2. Breve referencia sobre los antecedentes y el estado actual de la temática en Argentina y Brasil. 2.1. El antecedente brasilero. 2.2. El estado actual en la Argentina. 2.2.I. La Ley de Defensa de los Consumidores y Usuarios. 2.2.2. La protección de los consumidores en la Constitución Nacional argentina. 2.2.3. El nuevo Código Civil y Comercial Unificado. 3. La inespecificidad de las asociaciones de consumidores en Argentina. 4. La dispersión y falta de cohesión de los consumidores y usuarios. 5. Propuestas de solución a la inespecificidad de las asociaciones y a la dispersión de los consumidores en Argentina. 5.I. Procedimiento de determinación y especificación de las asociaciones de consumidores. 5.2. Medidas para lograr la cohesión de los consumidores. 6. Conclusiones. Lista de referencias.

\section{Introducción}

Como anticipamos en el resumen de este trabajo, pretendemos analizar una problemática cuya cuestión sería ¿cómo debe lograrse la representación de los consumidores en las convenciones colectivas de consumo?

Creemos necesario explicar al lector de dónde nos surge esta pregunta problema. 
El origen se remonta al año 2005 cuando, gracias a la Asociación de Universidades del Grupo Montevideo ("AUGM") pudimos estudiar un semestre en la Facultad de Derecho de la Universidad Federal de Río Grande do Sul, Porto Alegre, Brasil, bajo la dirección de la Profesora Dra. Claudia Lima Marques.

Desde esos momentos, nuestros inicios en la investigación científica, hemos desarrollado tareas de investigación que nos llevan a integrar hoy un Grupo de Investigaciones Consolidado en la Universidad Nacional del Nordeste, Argentina.

El antecedente inmediato es nuestra investigación respecto de "La protección del débil jurídico como meta del Derecho posmoderno: paralelismo entre el Derecho del Trabajo y el Derecho del Consumo". En ella logramos determinar que, entre otras instituciones, era perfectamente aplicable al Derecho del Consumo el instituto de los Convenios Colectivos de Trabajo.

Esta vinculación entre ambas materias surge particularmente de la clara posición vulnerable de ambas sujetos intervinientes en ellas: el trabajador y el consumidor. Posición débil que es destacada por Grillo Silva y Lunardelli Cavallazzi (20I3):

Conclui-se que as contradições presentes nas vivências de consumidores e trabalhadores são aparentes, vez que o relacionamento entre eles é mediado pela lógica da produtividade, do consumo e da precariedade, pois tais sujeitos estão inseridos em uma mesma sociedade de mercado. $O$ direito consumerista e o direito laboral, ao olharem para o outro, os vulneráveis além de suas fronteiras, podem repensar em si mesmos e instituir mecanismos regulatórios mais eficazes para assegurar dignidade, proteção e tutela aos "seus" vulneráveis.

Con este antecedente propusimos como tema de Tesis Doctoral (aprobado) el siguiente: "La protección del consumidor como débil jurídico mediante instituciones del Derecho del Trabajo argentino vigentes: las Convenciones Colectivas de Trabajo”, doctorado cuya finalización es financiada por el Consejo de Investigaciones Científicas y Técnicas (“CONICET”) de la República Argentina.

Pues bien, en la ardua tarea de hacer un aporte novedoso al Derecho del Consumo mediante los convenios colectivos de trabajo nos encontramos con la dificultad que tiene la aplicación de ese instituto del Derecho del Trabajo en el ámbito del consumo, debido especialmente a la legitimación de las asociaciones de consumidores y la falta de sentido de pertenencia al colectivo de los consumidores.

No obstante estas y otras dificultades, entendemos que el problema debe ser enfrentado y resuelto, con el objetivo de lograr cada día una mayor y mejor protección de un sujeto de por sí débil: el consumidor. 
Por ello dirá Lorenzetti (1994):

La existencia de principios de interpretación a favor del deudor evolucionó hacia el favor debilis, a favor del consumidor, y luego a favor del individuo en particular. La generalización hace que se pase de una visión bilateral a una estructural, que toma en cuenta la posición del individuo en el mercado. Esta extensión provoca que el Derecho Privado asuma un carácter defensivo del individuo en general, sin aditamentos (p. 54).

La importancia del tema radica en que todos los seres humanos del planeta somos consumidores, creando de esa manera un colectivo de individuos a proteger muy superior al Derecho del Trabajo, por cuanto la población económicamente activa y que trabaja en relación de dependencia es una porción pequeña de aquéllos que consumen.

Entendemos que las convenciones colectivas de consumo propenden y colaborarán en la realización de la igualdad formal a la igualdad real. En pos de esta igualdad real dirán Lima Marques y Miragem (2012):

A obra de von Hippel considera "os mais fracos" aqueles que estão diante de parceiros contratuais mais fortes (como o trabalhador e o consumidor)...(p. 9)

Em outras palavras, em tempos pós-modernos estes novos sujeitos identificados pelo direito reivindicarão sua própria lei, leis especiais subjetivas e protetivas do diferente, do vulnerável. Assim o serão o Código de Defesa do Consumidor, o Estatuto da Criança e do Adolescente, o Estatuto do Idoso, entre outros diplomas legais. Essas leis, então, acabam por abalar ou pelo menos modificar o sistema geral a que pertencia o sujeito, no caso, o direito civil. Trata-se, porém, de uma necessária concretização do princípio de igualdade, de tratamento desigual aos desiguais, da procura de uma igualdade material e momentãnea para um sujeito com direitos diferentes, sujeito vulnerável, mais fraco. A lei especial e os direitos a ele assegurados são aqui instrumentos de igualdade. (p. 16)

\section{Breve referencia sobre los antecedentes y el estado actual de la temática en Argentina y Brasil}

Habiendo explicitado los motivos por los cuales escogimos este tema para investigar y desarrollar, pasamos a tratarlo.

\section{I. El antecedente brasiler}

En el año 1990 se dicta en la República Federativa del Brasil la ley 8078/90 (8078, LGLI/990/40), que sancionó el Codigo de Defesa do Consumidor (en adelante, el “CDC”).

Este código trajo como novedad, en su artículo 107, la regulación de las llamadas convenciones colectivas de consumo, en los siguientes términos: 


\section{TÍTULO V}

\section{Da Convenção Coletiva de Consumo}

Art. 107. As entidades civis de consumidores e as associações de fornecedores ou sindicatos de categoria econômica podem regular, por convenção escrita, relações de consumo que tenham por objeto estabelecer condições relativas ao preço, à qualidade, à quantidade, à garantia e características de produtos e serviços, bem como à reclamação e composição do conflito de consumo.

$\S 1^{\circ}$ A convenção tornar-se-á obrigatória a partir do registro do instrumento no cartório de títulos e documentos.

$\S 2^{\circ} \mathrm{A}$ convenção somente obrigará os filiados às entidades signatárias.

$\S 3^{\circ}$ Não se exime de cumprir a convenção o fornecedor que se desligar da entidade em data posterior ao registro do instrumento. (planalto.gov.br - 2016)

Esta previsión legislativa dio por tierra con la exclusividad que tenía la convención colectiva de trabajo como método a utilizar por sujetos privados para regular colectivamente relaciones de derecho privado, conforme lo señala Rudiger (1993):

Procurando uma abordagem, na literatura do Direito Civil, sobre o contrato coletivo, depara-se com o fato de que a maioria dos autores, quando a ele se refere, aborda-o como contrato coletivo do trabalho. O Direito do Trabalho, portanto, aparece como única área do Direito Privado em que o instituto do contrato coletivo tem alguma importância. Examinando, porém, a questão do declínio da autonomia da vontade, a questão da técnica e do controle dos contratos por adesão, encontram-se vozes singulares na literatura que defendem a adoção dos contratos coletivos em outras áreas do Direito Privado. Principalmente nos casos em que se configura um desequilibrio entre as partes contratantes. Não há, entretanto, uma abordagem sistemática teórica sobre o assunto, nem na literatura estrangeira nem na literatura brasileira. E é justamente no Brasil que se faz necessária uma reflexão sobre o assunto, uma vez que o Código de Proteção e Defesa do Consumidor prevê em seu Título $V$ a convenção coletiva de consumo (p. 132).

\subsection{El estado actual en la Argentina}

\subsection{La Ley de Defensa de los Consumidores y Usuarios}

Con el claro precedente citado en el apartado anterior, en la República Argentina se dicta la ley 24240 (Ley 24240, 1993), de Defensa del Consumidor (en adelante, “LDC”). La LDC no reguló las convenciones colectivas de consumo.

Sí trató, en cambio, de las asociaciones de consumidores, tanto al regular las facultades de los organismos administrativos respecto de las mismas como en su accionar en defensa de los consumidores y usuarios. 


\subsubsection{La protección de los consumidores en la Constitución Nacional argentina}

Un año después del dictado de la LDC se dará en la República Argentina un hecho de trascendental importancia para el mundo jurídico de un país: la modificación de la Constitución Nacional (Constitución Nacional, 1853). Como resultado de esta reforma se introdujo en la Constitución un nuevo Capítulo, el capítulo Segundo de la Primera Parte, titulado "Nuevos derechos y garantías".

Allí se sancionó el artículo 42, que dispone:

Los consumidores y usuarios de bienes y servicios tienen derecho, en la relación de consumo, a la protección de su salud, seguridad e intereses económicos; a una información adecuada y veraz; a la libertad de elección, y a condiciones de trato equitativo y digno.

Las autoridades proveerán a la protección de esos derechos, a la educación para el consumo, a la defensa de la competencia contra toda forma de distorsión de los mercados, al control de los monopolios naturales y legales, al de la calidad y eficiencia de los servicios públicos, y a la constitución de asociaciones de consumidores y de usuarios.

La legislación establecerá procedimientos eficaces para la prevención y solución de conflictos, y los marcos regulatorios de los servicios públicos de competencia nacional, previendo la necesaria participación de las asociaciones de consumidores y usuarios y de las provincias interesadas, en los organismos de control. (infoleg.gob.ar - 2016)

Nuevamente, al igual que el caso de la LDC, la Constitución nada estableció respecto de la posibilidad de que existan convenciones colectivas de consumo, a diferencia de lo regulado en el segundo párrafo del artículo 14 bis de esta Constitución: "Queda garantizado a los gremios: concertar convenios colectivos de trabajo...". Es de resaltar que este artículo 14 bis fue introducido en la reforma constitucional del año 1957.

La diferencia radica en que, según el nuevo artículo 42 de la Constitución, "Las autoridades proveerán... a la constitución de asociaciones de consumidores y de usuarios", sin indicar qué hechos fundamentales podrán llevar adelante éstas.

Esto fue puesto de relieve por Bidart Campos (1996):

a) Antes de la reforma de 1994, la constitución formal no aludía a entes colectivos cuando titularizaba derechos, salvo en el reconocimiento a los "gremios" en el art. I 4 bis.

Después de la reforma, las remisiones que efectúan muchos artículos a dichos entes son susceptibles de emplearse para reconocerles determinados derechos. Tales menciones aparecen, por ej., en el art. 38 (partidos políticos); en el art. 42 (asociaciones de consumidores y usuarios); art. 43 (asociaciones que propenden a los fines tutelados mediante 
la acción de amparo del segundo párrafo de la norma); también art. 43 (asociaciones o entidades que poseen registros o bancos de datos públicos, o privados que están destinados a proveer informes, según el párrafo tercero dedicado al habeas data); art. 75 inc. 17 (personería jurídica de comunidades indígenas); art. 75 inc. 19 (universidades nacionales citadas en el párrafo tercero). (p. 498)

\subsubsection{El nuevo Código Civil y Comercial Unificado}

A partir de agosto del año 2015 rige en la República Argentina un nuevo código Civil y Comercial unificado. Este cuerpo normativo contempla en su Libro Tercero, Título III, de los "Contratos de consumo" todo lo relacionado a la materia en tratamiento, sin derogar la LDC.

Sin embargo, en sus previsiones (artículos 1092 a II22) nada dice respecto de la posibilidad de celebrar acuerdos colectivos, simplemente limitándose a regular las relaciones individuales de consumo. Es más, en todos esos artículos no se hace ninguna mención a las asociaciones de consumidores.

\section{La inespecificidad de las asociaciones de consumidores en Argentina}

Habiendo expuesto el motivo del presente estudio y las condiciones legislativas actuales en la República Argentina respecto de las convenciones colectivas de consumo (ausencia total de regulación), más nos llamó la atención al realizar el relevamiento bibliográfico tanto para la investigación general realizada durante tres años como becarios de iniciación científica como el nuevo relevamiento realizado en el marco del Doctorado que ningún autor de los que hemos tenido al alcance $y$ analizado haya mencionado expresamente las convenciones colectivas de consumo, reguladas en un país limítrofe como Brasil.

Ingresando al análisis específico de nuestro estudio, encontramos en la República Argentina una dificultad para la implementación de las convenciones colectivas, cual es la inespecificidad de las asociaciones de defensa de consumidores y usuarios. Nos explicamos: cualquier persona puede trabajar en defensa del colectivo de consumidores.

Ahora bien, si se trata de una persona jurídica que pretende representarlos debe tener la forma jurídica de una asociación civil. $Y$ si esta asociación civil quiere ir más allá y representar a los consumidores y usuarios de manera colectiva debe estar inscripta en un registro, que dependerá de cuan extensa sea la representación que pretenda.

Si pretende actuar defendiendo consumidores de una determinada provincia, bastará con que esté inscripta en el registro de asociaciones de consumidores de esa provincia, donde lo haya. Si no lo hay, bastará con la inscripción en el organismo que regule las personas jurídicas.

En cambio, si la asociación pretende representar a los consumidores y usuarios de toda la República Argentina deberá estar inscripta en un Registro Nacional creado al efecto. Sin embargo, para lograr 
la inscripción en ese registro no es necesario tener una finalidad específica más allá de la de representar a los consumidores y usuarios.

La Autoridad administrativa no exige que se represente a los usuarios de servicios financieros, usuarios de servicios bancarios, usuarios de servicios públicos de agua y saneamiento, etc. Con estar inscripta en el registro correspondiente la asociación podrá representar a todos los consumidores y usuarios de las más diversas relaciones de consumo (salvo, claro está, que la propia asociación se autolimite en cuanto a quienes pretende representar en su objeto estatutario).

Esta falta de especificidad y/o de representación de una clase específica entendemos constituye y constituirá un óbice a que las asociaciones puedan celebrar convenios colectivos de consumo, pues por ejemplo negociar con bancos precisa de conocimiento específicos profundos en materia bancaria, con empresas tecnológicas precisa de conocimientos de tecnología, y una asociación genérica no tendrá especialistas en todas las ramas a fin de cumplir adecuadamente sus fines.

Así lo pone de manifiesto Rudiger (1993):

À generalização da negociação coletiva das cláusulas gerais são feitas varias objeções: a) a representatividade das associações é questionável; b) o número de cláusulas gerais possíveis é muito grande; c) a comparação entre interesses coletivos de grupos e interesses difusos é dificil e d) o efeito erga omnes dos contratos coletivos de consumidores encontra dificuldades doutrinárias. (p. 132)

\section{La dispersión y falta de cohesión de los consumidores y usuarios}

Del estudio que venimos realizando en forma comparativa entre el Derecho del Trabajo y el Derecho del Consumo creemos poder concluir que este último está en el mismo estadio que el Derecho del Trabajo a inicios del siglo XX. La diferencia es que el hecho social del trabajo crea colectivos de personas con sentimiento de pertenencia a un medio común: la fábrica, el taller, la oficina.

Dirá Corte (1994):

La norma -como otras similares de ordenamientos precedentes- formula una de las premisas típicas del "modelo sindical" argentino, en el sentido de que la profesionalidad como condición objetiva de sindicalización (es decir, la pertenencia a una misma actividad, oficio, profesión, categoría o empresa) es la base de nucleamiento sindical en la República Argentina. (p. 164)

En cambio, el acto de consumo, si bien realizado por todos los seres humanos del planeta -en diversas medidas, obviamente-, no crea lazos de comunidad entre los consumidores. El acto de consumo o uso en los términos del Derecho del Consumo se da aisladamente, el consumidor frente al proveedor. 
Por ello la negociación colectiva se dificulta, ya que los consumidores no sienten pertenecer al universo de consumidores y no se sienten representados por las asociaciones de consumidores, a quienes ni siquiera conocen.

Konder Comparato (20II) concluye que "A solidariedade que se manifesta espontaneamente em nossa gente é de cunho afetivo e emocional, nunca de conteúdo voluntarista ou racional; ou seja, ela medra no âmbito familiar e entre os amigos, dificilmente nas relações de interesse" (p. 27)

\section{Propuestas de solución a la inespecificidad de las asociaciones y a la dispersión de los consumidores en Argentina}

Expuestos algunos de los problemas que enfrentamos en nuestra investigación respecto de la posibilidad de aplicar las convenciones colectivas de consumo en la República Argentina, pasamos a proponer tentativas de soluciones a los mismos.

\section{I. Procedimiento de determinación y especificación de las asociaciones de consumidores}

Como mencionamos precedentemente, las asociaciones que pretendan representar a los consumidores y usuarios de la República Argentina deben estar inscriptas en el registro nacional creado a tal efecto por el art. $1^{\circ}$ de la Resolución 46I/1999 de la Secretaría de Industria, Comercio y Minería de la Nación (Resolución SICM 46I, 1999), de asociaciones de consumidores.

Para lograr su inscripción en ese registro las asociaciones deben acreditar una serie de requisitos señalados en la Resolución indicada, cumplidos los cuales la Autoridad administrativa ordena su inscripción en el registro, lo que la autoriza a representar al colectivo sin necesidad de mandato específico por cada uno de los representados.

Entendemos que en ese procedimiento de inscripción debe establecerse como requisito que el objeto social de la asociación sea específico respecto del universo de consumidores o usuarios a representar.

Básicamente se trata de lo que, por el hecho social mismo del trabajo, se cumple en las asociaciones sindicales de trabajadores -de base, no hablamos de confederaciones-. Ninguna asociación sindical representa a los trabajadores de la República Argentina sin más, sino que representa a los empleados de comercio, obreros de la construcción, empleados de la sanidad, etc.

En la República Argentina existen asociaciones de consumidores con objeto específico (por ejemplo, "Consumidores Financieros, asociación civil para su defensa"), pero esta especificidad se debe a una autolimitación de los miembros de la asociación, y no como un requisito necesario para su funcionamiento como ente colectivo representante de intereses colectivos. 
Creemos que debe propenderse al establecimiento del requisito de especificidad a fin de que quienes representen a los consumidores y/o usuarios en un sector específico de la economía sean expertos en ese sector, asegurando de esa manera mejores resultados en la defensa de los consumidores.

Esto sin perjuicio de levantar una alerta: este requisito no debe ser de cumplimiento tan específico que haga imposible el funcionamiento de las asociaciones, las que precisan de un cierto número de asociados a fin de proveer a su sustento y mantenimiento. Al igual que el atomismo sindical, que debilita al colectivo de los trabajadores, el excesivo fraccionamiento de las asociaciones por causa de su objeto puede hacer ilusoria la pretensión de defensa de los mismos.

Para concluir, hacemos nuestra la exposición realizada por Prada Alonso (1998), pidiendo disculpas al lector por el abuso en la extensión de la cita, pero entendimos que mutilarla sería hacerla perder su valor doctrinario:

En relación a ellos, el individuo sólo no puede defenderse y debe tomarse conciencia de que cada vez es más importante al consumidor organizarse en asociaciones para defenderse de los abusos de que es objeto, dando entrada así a los intereses colectivos. (p. 16)

Los intereses colectivos adquieren un espacio de protección seguro cuando en su tutela participan instancias que los representan directamente. Por mucho interés que ponga, el individuo aislado no está en condiciones de asegurar una protección adecuada y los poderes públicos, por muchos medios de que dispongan, no van a ser capaces de abarcar el extraordinariamente amplio campo que ofrece el consumo, por lo que es obvio que para la garantía y protección de los derechos de los consumidores hay que contar con las asociaciones públicas o privadas que se dediquen a ese fin, cuya colaboración y concurso se han mostrado útiles (así, las diferentes asociaciones, ya a nivel provincial y nacional, en el asunto del llamado aceite de colza o síndrome tóxico, opino mejor, síndrome inespecífico). Con ellos se pueden obviar los defectos, deficiencias y falta de medios de que adolece el individuo particular, al tiempo que podrán hacer más efectivo el control mediante personas especializadas de aquellos sectores en los que las denuncias son más escasas e inciertas... (p. II5)

Las facultades reconocidas a los mismos deben ser al menos dos: participación y consulta en la toma de decisiones y en la elaboración de las normas reguladoras de materias que afecten en la toma de decisión y en la elaboración de las normas reguladoras de materias que afecten a los consumidores y de representación y defensa, incluso judicial, de los intereses de los consumidores en general, sean o no asociados de la misma... (p. II5)

\subsection{Medidas para lograr la cohesión de los consumidores}

Otro de los problemas señalados es el excesivo aislamiento de los consumidores (que no tienen sentimiento de pertenecer a una clase) lo que dificulta el accionar de las asociaciones de consumidores. 
Entendemos que ello se debe a la naturaleza misma del ser humano, cuyo sentido de pertenecía se limita a su familia nuclear y amistades más cercanas, no percibiendo la comunidad que forma junto al resto de los habitantes de su ciudad, país.

Creemos que, con la especificación de las asociaciones de consumidores propugnadas en el apartado anterior, puede lograrse por parte de los consumidores una mayor identificación con la clase a la cual el acto de consumo le hace pertenecer.

No habiendo cien asociaciones de consumidores, sino una que representa acabadamente, por ejemplo, a los usuarios de servicios domiciliarios de agua potable, será más fácil que ellos al precisar de ayuda conozcan con certeza qué asociación los representa.

Unido a ello, y de igual manera que con las asociaciones sindicales, entendemos que debería gravarse en la fuente -cada acto de consumo- una suma ínfima con destino a la asociación de consumidores y usuarios respectiva, a fin de colaborar con su financiamiento y funcionamiento.

Así, siguiendo con el ejemplo anterior, cuando al usuario del servicio domiciliario de agua potable le sea enviada la factura con su consumo mensual, en la misma debería haber un ínfimo porcentual en los rubros facturados con destino a la asociación respectiva, el que podrá variar dependiendo que el usuario se quiera afiliar a la misma o simplemente se le imponga el cargo coactivamente (de la misma manera que todo trabajador contribuye a la asociación sindical que lo representa en diversas medidas, dependiendo de su afiliación o no, pero sí o sí contribuye).

Esta contribución no sólo ayudará a la asociación respectiva, sino que sobre todo creará en el usuario la autoafirmación de su derecho de requerir la ayuda de la asociación llegado el caso, pues al contribuir a su financiamiento tendrá expectativas de que la asociación lo defienda ("Si yo pago para sostenerla...”).

\section{Conclusiones}

Por las breves líneas antecedentes esperamos haber llamado la atención de los lectores respecto de un tema relativamente novedoso y poco tratado, las convenciones colectivas de consumo, y dentro de ellas la representación de los consumidores.

Entendemos que en el estadio actual de la institución se encuentra una excesiva dispersión y poca especificidad en las asociaciones de consumidores y usuarios, lo que lleva a que la fuerza agrupacional de las mismas se diluya sin impactos significativos en el mercado de consumo.

Como en el Derecho del Trabajo, esperamos que un mayor desarrollo del tema y una profesionalización de las asociaciones, mediante el otorgamiento por la Autoridad administrativa de un similar a la personería gremial en el ámbito laboral a las asociaciones sindicales, lleve a que una de ella se erija como suficientemente representativa y provea a la ayuda de los consumidores y usuarios. 
Para ello sería deseable, como primer objetivo de corto plazo y mayor factibilidad de realización, lograr la reforma de la LDC que imponga la readecuación de los objetivos sociales estatutarios de las asociaciones de consumidores, propendiendo así a la mayor especificidad.

Junto con esta exigencia, también introducirse mediante ley del Congreso de la Nación el impuesto al consumo destinado a las asociaciones, a fin de lograr su sostenimiento.

A mediano/largo plazo es deseable una modificación de la Constitución Nacional en el sentido de brindar una regulación más detallada de las asociaciones de consumidores, así como la contenida en el artículo 14 bis de la Constitución Nacional respecto de las asociaciones de trabajadores, a las cuales debida un párrafo detallando sus derechos y los derechos de los representantes de los trabajadores

\section{Lista de referencias}

Bidart Campos, G. J. (1996). Manual de la Constitución reformada. Buenos Aires, Argentina: Ediar, tomo I.

Corte, N. T. (1994). El Modelo Sindical Argentino. $2^{\mathrm{a}}$ Ed. Santa Fe, Argentina: Rubinzal-Culzoni.

Grillo Coutinho Leonardo da Silva, S. - Lunardelli Cavallazzi, R. (20I3). Vulnerabilidade e direitos: lei e jurisprudência sobre consumo e trabalho na sociedade contemporânea. Revista de Direito do Consumidor, vol. 86/2013, março de 2013. Cita: DTR/2013/3083.

http://servicios.infoleg.gob.ar/infolegInternet/anexos/0-4999/638/norma.htm. Ley 24240. Sancionada el 22 de septiembre de 1993. Consultada el 07 de septiembre de 2016 a las 09:53 horas.

http://servicios.infoleg.gob.ar/infoleglnternet/anexos/0-4999/804/norma.htm.

Constitución

Nacional. Sancionada el $1^{\circ}$ de mayo de 1853, con las reformas de los años 1860, 1866, I898, 1957 y 1994. Consultada el 07 de septiembre de 2016 a las 18:05 horas.

http://servicios.infoleg.gob.ar/infolegInternet/anexos/55000-59999/58624/texact.htm. Resolución Secretaría de Industria, Comercio y Minería № 46I. Sancionada el 02 de julio de 1999. Consultada el 03 de febrero de 2017 a las 19:27 horas.

Konder Comparato, F. (20II). A proteção do consumidor. Importante capítulo do direito econômico. Revista de Direito do Consumidor, vol. 77, p. 27, janeiro de 20II. Cita: DTR/20I I/I2I8.

Lima Marques, C.- Miragem, B. (20I2). O novo Direito privado e a proteção dos vulneráveis. Revista dos Tribunais, São Paulo. 
Lorenzetti, R. L. (1994). El Derecho privado como protección del individuo particular. Revista de Derecho Privado y Comunitario 7, "Derecho Privado de la reforma constitucional”, Rubinzal-Culzoni Editores, Santa Fe, Argentina.

https://www.planalto.gov.br/ccivil_03/Leis/L8078.htm. Dictada el II de septiembre de 1990. Consultada el 07 de septiembre de 2016 a las 08:10 horas.

Prada Alonso, J. (1998). Protección del consumidor y responsabilidad civil. Madrid, España: Marcial Pons.

Rudiger, D. S. (1993). Contratos coletivos, contratos de direito civil e proteção do consumidor. Revista de Direito do Consumidor, vol. 5, janeiro de 1993. Cita: DTR/I993/579. 